\title{
BEHAVIORISMO METODOLÓGICO
}

\author{
METHODOLOGICAL BEHAVIORISM
}

\author{
JAY MOORE
}

\section{UNIVERSITY OF WISCONSIN-MILWAUKEE, ESTADOS UNIDOS}

\section{RESUMO}

As abordagens iniciais da psicologia supunham que a vida mental era o assunto apropriado desta nova ciência e que relatos verbais introspectivos e os tempos de reação eram os métodos apropriados para dar suporte às inferências sobre esse assunto. O problema foi que essas abordagens iniciais eram vagas, pouco confiáveis e geralmente ineficazes. $\mathrm{O}$ behaviorismo metodológico surgiu como uma tentativa de lidar com esse problema, afirmando que as teorias e explicações em psicologia, bem como os conceitos que eles implantaram, devem ser acordados. A chave para este acordo era que os psicólogos deveriam falar apenas do que é observável, embora falar de eventos mentais inobserváveis fosse posteriormente permitido se fossem designados como construtos teóricos que eram definidos operacionalmente por meio de sua relação com os eventos observáveis. Essa visão posterior permanece proeminente na psicologia tradicional. $\mathrm{O}$ behaviorismo radical da análise do comportamento de B. F. Skinner oferece uma alternativa baseada em uma análise crítica das fontes comportamentais de controle sobre um determinado termo. Em particular, o conceito behaviorista radical de eventos comportamentais privados fornece uma explicação unificada da natureza em termos comportamentais.

Palavras-chave: comportamento verbal, behaviorismo metodológico, behaviorismo radical, operacionalismo, previsão e controle, eventos comportamentais encobertos, lei de cobertura, método científico

Early approaches to psychology assumed that mental life was the appropriate subject matter of the new science, and that introspective verbal reports and reaction times were the appropriate methods to support inferences about that subject matter. The problem was that these early approaches were vague, unreliable, and generally ineffective. Methodological behaviorism arose as an attempt to deal with this problem by asserting that theories and explanations in psychology, as well as the concepts they deployed, should be agreed upon. The key to agreement was that psychologists should talk only about observables, although talk of mental unobservables was later permitted if they were designated as theoretical constructs that were operationally defined through their relation to observables. This later view remains prominent in traditional psychology. The radical behaviorism of B. F. Skinner's behavior analysis offers an alternative based on a critical analysis of the behavioral sources of control over a given term. In particular, the radical behaviorist concept of private behavioral events provides a unified account of nature in behavioral terms.

Key words: verbal behavior, methodological behaviorism, radical behaviorism, operationism, prediction and control, private behavioral events, covering law, scientific method

\footnotetext{
Este artigo é derivado de um material que desenvolvi no decorrer dos anos para me auxiliar em minhas aulas sobre o behaviorismo metodológico. Ofereço este material aqui na esperança de que seja útil. De acordo com a meta instrucional deste artigo, as referências são mínimas. Adicionalmente, tanto a linguagem quanto os argumentos são mais informais do que em outros artigos. Peço desculpas e a tolerância dos leitores caso falhe na execução. Posso apenas dizer que as contingências ainda não terminaram comigo. Contato: jcm@uwm.edu, or at his home address: 1861 E. Fox Lane; Fox Point, WI 53217; USA.
}

Tradução: Hernando Borges Neves Filho (Pós-Doutorando do Programa de Pós-Graduação em Teoria e Pesquisa do Comportamento da Universidade Federal do Pará). 


\section{METHODOLOGICAL BEHAVIORISM}

O behaviorismo metodológico é uma tese prescritiva sobre como fazer psicologia. Subjacente à tese, está a afirmação de que a ciência exige consenso. Então, dado que se pode alcançar acordo em relação a eventos observáveis e quanto aos inobserváveis não, a tese sustenta que as teorias e explicações psicológicas, assim como os conceitos que elas empregam, devem ser expressas em termos de eventos publicamente observáveis, como variáveis e relações, em contraposição a fenômenos mentais não observáveis. Esta tese surgiu durante o primeiro trimestre do século XX. No entanto, a tese foi interpretada de, pelo menos, duas maneiras diferentes nos últimos 100 anos.

\section{PRIMEIRA INTERPRETAÇÃO SOBRE O BEHAVIORISMO METODOLÓGICO}

A primeira e original interpretação do behaviorismo metodológico foi que as teorias e explicações psicológicas deveriam apenas descrever relações entre estímulos e respostas publicamente observáveis, por exemplo, em um modelo S-R, e deveriam permanecer em silêncio sobre todo o resto. Psicólogos poderiam até supor que existiam causas mentais. No entanto, tais causas não deveriam ser incluídas diretamente nas teorias e explicações psicológicas. Qualquer coisa sobre o mental deveria ser tratada por outra disciplina, como a filosofia ou a religião, mas não a ciência, que precisava de consenso por meio da observabilidade. Psicólogos poderiam supor ainda que as explicações desenvolvidas sob esta primeira interpretação seriam cientificamente satisfatórias. Esta interpretação inicial ainda tem alguns defensores, mas começou a perder popularidade por volta de 1930. Desde 1950, uma segunda interpretação substituiu amplamente a primeira.

\section{SEGUNDA INTERPRETAÇÃO SOBRE O BEHAVIORISMO METODOLÓGICO}

A segunda interpretação é que os psicólogos podem sim incluir eventos inobserváveis em suas teorias e explicações, mas somente se estes eventos inobserváveis são designados como construtos teóricos (por exemplo, construtos lógicos, termos teóricos) e operacionalmente definidos. A definição operacional especifica os fatores publicamente observáveis envolvidos na medição do construto. Um construto pode muito bem ser usado para se referir a algum fenômeno mental ou cognitivo não observável, já que a definição operacional em termos de eventos observáveis torna o construto cientificamente respeitável porque se pode obter acordo quanto à evidência do fenômeno mental. Por exemplo, o construto poderia ser operacionalmente definido em termos de (a) medidas comportamentais (por exemplo, tomando o tempo de reação para indicar a velocidade na qual algum processo mental é dito operar) ou (b) medidas fisiológicas (por exemplo, com uma tecnologia mais contemporânea, usar fMRI para revelar correlatos neurais de processos mentais). Desta forma, os eventos inobserváveis são incluídos apenas indiretamente, não diretamente. Como resultado, a abordagem é tomada como satisfatória no que tange a preocupações científicas.

$\mathrm{O}$ método comum associado à segunda interpretação é inferir uma variável "O" ("organísmica") dentro do organismo, como um construto teórico. A função deste construto é mediar a relação entre $\mathrm{S}$ e R. Mediar significa que os estímulos externos observáveis ativam ou acionam uma ou mais entidades intervenientes ou mediadoras não observáveis que são causalmente conectadas de alguma forma complexa, mas sistemática, a uma resposta observável subsequente. O resultado é que o sujeito é mantido em contato apenas com a entidade mediadora, não com o ambiente externo observável. Um nome genérico para essa abordagem é o neocomportamentalismo S-O-R. Teorias da aprendizagem como as de Tolman ou Hull-Spence, são exemplos. Uma abordagem mediacional com construtos teóricos operacionalmente definidos é atualmente a mais popular, porque permite que pesquisadores e teóricos mantenham suas causas mentais no sistema.

\section{DEFINIÇÕES OPERACIONAIS PARCIAIS OU EXAUSTIVAS?}

De meados da década de 1930 até o final da década de 1940, psicólogos debateram outro assunto relacionado com a segunda interpretação (MacCorquodale \& Meehl, 1948). Este debate se ateve a discutir se a definição operacional de um construto teórico deve ser considerada como exaustiva (ou seja, interpretação do construto como variável interveniente) ou parcial (ou seja, interpretação como construto hipotético). De acordo com esta distinção, como proposta por MacCorquodale e Meehl, se o construto teórico não é usado ou aplicado em nenhuma outra situação além da atual, então sua definição operacional em termos do uso ou aplicação atual fornece o significado total para o construto, e seu significado como expresso em termos do uso ou aplicação atual é considerado exaustivo. Em termos simples, o construto não tem significado adicional. Além disso, como uma definição exaustiva fornece apenas um resumo econômico da situação atual, não se presume que o construto se refira a alguma variável que realmente exista.

Alternativamente, como MacCorquodale e Meehl (1948) também escreveram, se o construto é usado ou aplicado em outras situações, então sua definição em termos do uso ou aplicação atual fornece apenas um de seus vários significados possíveis. Esses outros usos ou aplicações fornecem seus próprios significados, e outros usos ou aplicações não examinados sugerem ainda mais significados a serem descobertos. Se assim for, então o seu significado expresso em termos do uso ou aplicação atual é considerado apenas parcial. Em termos simples, o construto tem um significado excedente. Em qualquer caso, como uma definição parcial admite múltiplos usos ou aplicações, pode-se supor que o construto se refira a alguma variável que realmente existe. Se não, como poderia ter múltiplos usos ou aplicações? Desde o final da década de 1940, psicólogos têm favorecido a interpretação do construto hipotético, na medida em que ele produz maior generalidade e flexibilidade no desenvolvimento de 
teorias e explicações. Alguns escritores podem até rotular a interpretação do construto hipotético como uma terceira interpretação do behaviorismo metodológico, em vez de uma variação da segunda.

\section{INFLUÊNCIA DO BEHAVIORISMO METODOLÓGICO NO MÉTODO CIENTÍFICO}

Finalmente, um conjunto particular de pesquisas e práticas explicativas também foi desenvolvido em conjunto com a segunda interpretação do behaviorismo metodológico. De acordo com essas práticas, a forma apropriada de pesquisa consistia em formular teorias S-O-R sobre a mediação de variáveis organísmicas (o "O" acima). Previsões (isto é, deduções) dessas teorias são então testadas sob condições controladas usando vários grupos experimentais de acordo com um projeto experimental convencionalmente aprovado, com variáveis independentes e dependentes publicamente observáveis, termos teóricos operacionalmente definidos, e assim por diante. Os dados resultantes são avaliados usando estatísticas inferenciais de hipótese nula para determinar a probabilidade de que quaisquer diferenças observadas sejam atribuíveis ao acaso. Resultados consistentes com as previsões das teorias são tomados para validar a teoria que apela à variável mediadora. Uma vez validada, a teoria é elevada ao status de uma lei, e toda a abordagem, chamada abordagem de "lei de cobertura", é usada para explicar o evento em questão. Juntas, essas práticas são codificadas em cursos de estatística e desenho experimental na maioria dos livros didáticos e currículos universitários.

\section{POR QUE ALGUNS PSICÓLOGOS DEFENDEM O BEHAVIORISMO METODOLÓGICO?}

Durante o primeiro quarto do século $\mathrm{XX}$, as abordagens introspectivas clássicas da psicologia (por exemplo, estruturalismo, funcionalismo) falavam de eventos, variáveis e relações que eram inobserváveis e, portanto, sobre as quais não se podia obter acordo ou consenso. Por exemplo, o que significa dizer que um psicólogo estava investigando a "textura" da "sensação de verde"? O behaviorismo metodológico, conforme representado na primeira interpretação apresentada acima - permanecendo em silêncio sobre qualquer coisa que não fosse observável e falando apenas das relações observáveis S-R - surgiu na tentativa de resolver essas preocupações, enfatizando eventos, variáveis e relações sobre as quais se poderia obter acordo, passíveis de consenso. Depois de alguns anos, a maioria dos psicólogos chegou a pensar que a primeira interpretação era afinal restritiva demais e não era cientificamente satisfatória - tinha dificuldade considerável em acomodar a riqueza e a flexibilidade do comportamento. Algo epistemologicamente mais sofisticado do que os eventos observáveis de um modelo $\mathrm{S}-\mathrm{R}$ parecia ser necessário. Afinal de contas, outras ciências - notadamente a física teórica - pareciam ter avançado postulando eventos inobserváveis na forma de construtos teóricos, então por que a psicologia não deveria ter as mesmas técnicas?

A segunda interpretação ganhou destaque, portanto, quando psicólogos perceberam que novas ideias sobre o desenvolvimento de teorias baseadas no operacionismo não exigiam que os psicólogos permanecessem em silêncio sobre o mental. Incluir causas mentais não observáveis como construtos teóricos operacionalmente definidos foi julgado como cientificamente legítimo e não conflitivo com a tese do behaviorismo metodológico. Mais uma vez, essa abordagem indireta permitiu que os psicólogos concordassem com o significado de eventos inobserváveis o que permitiu que toda esta empreitada fosse considerada científica.

\section{POR QUE OS BEHAVIORISTAS RADICAIS SE OPÕEM AO BEHAVIORISMO METODOLÓGICO?}

Behavioristas radicais concordam que as abordagens introspectivas clássicas da psicologia são um problema. Behavioristas radicais também concordam que tentativas de reduzir todas as formas de comportamento a um modelo $\mathrm{S}$ $\mathrm{R}$ com apenas fatores observáveis são um problema. No entanto, os behavioristas radicais rejeitam o behaviorismo metodológico como solução por uma, ou usualmente ambas, das razões a seguir. Primeiro, ao negar ou ignorar certos eventos dentro da pele, as duas interpretações do behaviorismo metodológico aqui apresentadas falham em abordar um aspecto importante do comportamento humano, por não aceitar que esses eventos podem ser entendidos como fundamentalmente comportamentais por natureza e funcionalmente relacionados a antecedentes e consequências do ambiente. Na verdade, muitos desses eventos dentro da pele têm que ser tratados inferencialmente. No entanto, até que a nossa tecnologia avance ao ponto de eles possam ser tratados diretamente, parece não haver uma boa razão para tomar esses eventos como fora de consideração apenas porque eles não são acessíveis do ponto de vista de um observador.

Em segundo lugar, a segunda interpretação do behaviorismo metodológico aceita implicitamente uma visão mentalista do comportamento de ambos (a) o sujeito ou participante e (b) o cientista. Como vimos, os behavioristas metodológicos comumente atribuem o comportamento de um sujeito às variáveis "O" mediadoras. A origem das variáveis "O $\mathrm{O}$ " está no mentalismo, o que torna todo o empreendimento pouco mais do que um mentalismo disfarçado. Além disso, o comportamento de um cientista é similarmente concebido em termos mentalistas, em virtude da afirmação de que tratar causas mentais de comportamento como construtos teóricos operacionalmente definidos torna a abordagem cientificamente respeitável. Um construto teórico não é o mesmo que um estímulo discriminativo em contingências verbais operantes. Pelo contrário, é considerado um dispositivo lógico que faz parte da explicação mentalista e não-comportamental do comportamento verbal. Fundamental na explicação é a suposição de que palavras são símbolos que possuem entidades chamadas de "significados" que estão ligados a elas. Em contraste, para behavioristas radicais, o engajamento na ciência é um comportamento operante tipicamente verbal. Nesse sentido, o comportamento científico - verbal e não verbal - pode ser analisado em termos de contingências. Argumentar em termos de construtos move a análise do comportamento científico do domínio das relações comportamentais e contingências 
verbais para o domínio de uma metafísica mentalista e uma epistemologia mentalista sobre ambos, participantes e cientistas.

Em última análise, os behavioristas radicais argumentam que o behaviorismo metodológico é problemático em bases pragmáticas, assim como qualquer outra forma de mentalismo: ele não leva a previsão e controle efetivos, apesar de qualquer afirmação de que o operacionalismo garante a integridade científica dos conceitos inobserváveis. Os behavioristas radicais argumentam que, infelizmente, o behaviorismo metodológico é a posição ortodoxa na teorização psicológica contemporânea.

Certamente, as definições operacionais são muito importantes para a ciência, mas em um sentido diferente do que no behaviorismo metodológico. Ou seja, definições operacionais não tornam quaisquer eventos mentais em um evento cientificamente legítimo, como os behavioristas metodológicos supõem. Em vez disso, as definições operacionais ajudam a identificar até que ponto as operações científicas e os dados resultantes, em oposição à tradições socioculturais, práticas linguísticas e metáforas falhas, participam das contingências que governam nossos termos analíticos e explicativos. O operacionismo tradicional e o behaviorismo metodológico adotam uma visão mentalista e referencial do comportamento verbal, e institucionalizam o mentalismo sobre o comportamento de sujeitos ou participantes, de um lado, e sobre o cientista que teoriza e procura explicar esse comportamento, de outro. Em particular a postura epistemológica deste último pode ser designada como um dualismo epistemológico, na medida em que ele, inconscientemente, defende estratégias mentalistas para lidar com o que ele aceita como causas mentais do comportamento de sujeitos ou participantes.

\section{EVENTOS COMPORTAMENTAIS PRIVADOS}

Um tópico de interesse para muitos pesquisadores e teóricos ao longo dos desenvolvimentos analisados acima foi a questão sobre como incorporar eventos que são acessíveis apenas ao indivíduo que está se comportando. Skinner (1945, 1953) escreveu extensivamente sobre esse assunto quando escreveu sobre eventos comportamentais privados. Os dois tipos de eventos privados foram (a) relatos verbais sobre as condições e sensações do corpo, e (b) comportamento operante encoberto. $\mathrm{O}$ primeiro tipo inclui falar sobre nossas dores e sofrimentos no corpo. O segundo tipo incluiu os tópicos da consciência, consagrados pelo tempo, como um repertório de comportamento autodescritivo com valor discriminativo, e o pensamento, entendido como comportamento encoberto variado, desde devaneios até comportamento auto-analítico que também contribui para o controle discriminativo.
Para usar o segundo tipo de eventos privados como exemplo, pode-se dizer que esses eventos não faziam parte de um domínio mental mediador, como no neobehaviorismo SO-R. Em vez disso, esses eventos estavam no domínio comportamental e não parecia haver uma boa razão para excluí-los simplesmente porque eles não eram observáveis para os outros. Eles foram executados pelos mesmos sistemas de resposta que formas abertas de comportamento, apenas reduzidos em escala. Eles provavelmente foram até mesmo adquiridos de forma aberta, depois recuaram para o nível encoberto, porque as formas públicas foram punidas ou porque as formas encobertas eram convenientes. Skinner ofereceu uma interpretação de tais eventos em termos de comportamento operante e contingências de reforço nas quais a comunidade verbal desempenhou um papel significativo. Embora os eventos privados de outros possam ser inferidos por observadores, eles não são inferências para aqueles nos quais ocorrem. Pelo contrário, elas são uma função dos mesmos tipos de variáveis e relações que participam de eventos publicamente observáveis.

\section{ANÁLISE DO COMPORTAMENTO E TERMOS MENTAIS}

Os analistas do comportamento argumentam que o mentalismo é a orientação explicativa dominante na psicologia. Em linguagem simples, o mentalismo consiste no apelo a estruturas inobserváveis de um domínio não comportamental em explicações causais de comportamento. Normalmente, o domínio é o da "mente". Além disso, os analistas do comportamento se opõem ao mentalismo. Certamente, algumas teorias e explicações psicológicas contêm termos e conceitos que, à primeira vista, parecem ser mentais. No entanto, para analistas do comportamento, alguns desses termos e conceitos não são realmente mentalistas porque não apelam para entidades causais de um domínio não comportamental. Em vez disso, eles refletem eventos genuínos, variáveis e relações dignas de estudo por si mesmos.

As cinco categorias da tabela abaixo (Tabela 1) sugerem uma maneira de entender termos comumente considerados termos mentais. Os termos nas colunas 1-4 da tabela refletem observações e extensões no mesmo domínio em que o comportamento ocorre. Assim, esses termos nos ajudam a entender como o comportamento está relacionado às circunstâncias ambientais. No entanto, os termos não afetam as causas do comportamento. As causas do comportamento estão nas contingências. Em geral, os termos refletem várias características ou aspectos dos eventos comportamentais gerados pelas contingências. Vamos agora rever estes termos (Tabela 1).

Tabela 1.

Tipos de Termos Mentais

\begin{tabular}{lllll}
\hline $\begin{array}{l}\text { Eventos comportamentais } \\
\text { privados }\end{array}$ & Fisiologia & $\begin{array}{l}\text { Disposições } \\
\text { comportamentais }\end{array}$ & $\begin{array}{l}\text { Relações } \\
\text { comportamentais }\end{array}$ & Ficções explicativas \\
\hline Relatos verbais & $\begin{array}{l}\text { Lacuna para } \\
\text { dentro }\end{array}$ & Atitudes proposicionais & Atenção & $\begin{array}{l}\text { Psicologia popular [senso } \\
\text { comum] }\end{array}$ \\
Operantes encobertos & Lacuna entre & Idioma intencional & $\begin{array}{l}\text { Discriminação } \\
\text { Generalização }\end{array}$ & $\begin{array}{l}\text { Práticas de linguagem } \\
\text { Metáforas inapropriadas }\end{array}$ \\
\hline
\end{tabular}


- Os termos da coluna 1 têm sua fonte de controle em eventos comportamentais privados. Esses termos tateiam relatos verbais sobre sensações e sentimentos internos (por exemplo, declarações sobre experiências pessoais que envolvem dor, prazer, ansiedade) ou operantes encobertos (por exemplo, pensar, resolver problemas).

- Os termos da coluna 2 têm sua fonte de controle na fisiologia. Estes termos tateiam processos fisiológicos nas lacunas dentro de um evento comportamental (por exemplo, recrutamento) ou entre eventos comportamentais (por exemplo, a consolidação).

- Os termos da coluna 3 têm uma fonte de controle nas disposições comportamentais. Esses termos tateiam a probabilidade de uma forma particular de comportamento em determinadas circunstâncias (por exemplo, atitudes proposicionais, expressões idiomáticas intencionais: crença, desejo, intenção).

- Os termos da coluna 4 têm sua fonte de controle nas relações de controle de estímulo. Esses termos tateiam a influência das circunstâncias ambientais antecedentes sobre o comportamento (por exemplo, atenção, discriminação, generalização).

Os termos relacionados à coluna 5 podem ser atribuídos mais a fatores sociais estranhos e irrelevantes, como conformidade com a autoridade ou aceitação não crítica de convenções sociais e práticas culturalmente condicionadas, do que à relação de tato. Quando citadas como causas, os termos com essas fontes de controle são simplesmente ficções explicativas: supostos atos, estados, mecanismos, processos, entidades e estruturas (por exemplo, codificação, representações, recuperação de armazenamento) em um suposto domínio (por exemplo, hipotético, cognitivo, mental, espiritual, psíquico ou subjetivo) que difere do domínio comportamental. Esses termos surgem em grande parte através de processos ecoicos, textuais e intraverbais espúrios. Esses supostos atos, estados etc. são evidentes na psicologia popular, e também em nossos apelos a metáforas inadequadas, que decorrem de nossas práticas linguísticas, como quando convertemos adjetivos e advérbios em substantivos e então assumimos que os substantivos então representam atos causais, estados, etc. que realmente existem em um domínio mental não comportamental. Os termos com essas fontes de controle são problemáticos porque acabam levando às práticas contraproducentes do mentalismo e do behaviorismo metodológico. Em grande parte da psicologia contemporânea, esse comportamento verbal mentalista assume ironicamente a forma de um modelo de neobehaviorismo S-O-R, mediacional. Em vez de usar alguma medida observável como aproximação para uma estrutura mental não observável, como no operacionismo tradicional e no behaviorismo metodológico, o conceito de análise operacional de termos psicológicos de Skinner está relacionado à identificação das fontes de controle sobre o comportamento verbal em questão, de modo a poder avaliar se o comportamento verbal em questão pode contribuir para uma ciência eficaz do comportamento.

Termos-chave e conceitos: comportamento verbal, behaviorismo metodológico, behaviorismo radical, oparacionismo, predição e controle, eventos comportamentais privados.

\section{REFERÊNCIAS}

MacCorquodale, K., \& Meehl, P. (1948). On a distinction between hypothetical constructs and intervening variables. Psychological Review, 55, 95107. doi: 10.1037/h0056029

Skinner, B. F. (1945). The operational analysis of psychological terms. Psychological Review, 52, $27-$ 277, 290-294. doi: 10.1037/h0062535

Skinner B. F. (1953). Private events in a natural science. In B. F. Skinner, Science and Human Behavior (pp. 257-282). New York: Macmillan.

Submetido: 28/03/2018

Aceito: 21/04/2018 